American Journal of Orthopedic Research and Reviews
(ISSN:2637-4730)

\title{
Open Latarjet procedure for the management of anterior instability of the glenohumeral joint
}

Hatim ABID, Mohammed EL IDRISSI, Abdelhalim EL IBRAHIMI, Abdelmajid ELMRINI

Department of osteoarticular surgery B4, HASSAN II teaching hospital, Fes, Morocco

\section{ABSTRACT}

We report in the light of a literature review the results of 10 patients followed for anterior instability of the gleno-humeral joint treated by open Latarjet procedure between January 2017 and December 2020 with a view to a prospective study with longer following up and a greater number of patients.

Keywords: anterior instability; Surgery; Open Latarjet procedure.
*Correspondence to Author:

Hatim ABID

Imm 87, appt 4, rue Sidney, hay ouafae 2, narjiss, Fes; Morocco

How to cite this article:

Hatim ABID, Mohammed EL IDRISSI, Abdelhalim EL IBRAHIMI, Abdelmajid ELMRINI. Open Latarjet procedure for the management of anterior instability of the glenohumeral joint. American Journal of Orthopedic Research and Reviews, 2021, 4:21.

\section{eScîPub}

eSciPub LLC, Houston, TX USA.

Website: https://escipub.com/ 


\section{Introduction :}

Anterior shoulder instability is a challenging clinical problem, particularly among young active personnes with significant glenoid bone loss ${ }^{[1,2]}$. More than 150 operations have been described for the treatment of recurrent anterior dislocation of the shoulder. Transfer of the horizontal limb of the coracoid process through the subscapularis tendon and its fixation to the anteroinferior margin of the glenoid with a screw as described in 1954 by Latarjet is one of them ${ }^{[3,4]}$. We share through this article our experience concerning the management of Anterior shoulder instability by open Latarjet procedure performed in 10 young patients with a literature review.

\section{Patients and Method:}

Ten patients with Anterior shoulder instability were treated with open Latarjet procedure during the last 4 years between January 2017 and December 2020. We included patients with recurrent anterior instability, with or without hyperlaxity and with or without glenoid and/or humeral bone loss excluding anterior glenoid fractures involving more than one-third of the articular surface in which the coracoid does not provide enough bone for glenoid reconstruction.

Clinically, we perform a standardized preoperative clinical examination on all shoulders, including range of motion, rotator cuff testing, apprehension with relocation testing by insisting on the Gagey hyperabduction test which is a very useful examination tool for diagnosis inferior glenohumeral ligament distension ${ }^{[5]}$.

In our series, preoperative imaging studies included Antero-Posterior (AP) views in neutral, internal and external rotation in addition to glenoid profile views made bilaterally for comparison as described by Bernageau et al ${ }^{[6]}$. We performed the Computed Tomography arthrogram (CTA) in all our patients to assess the size of a glenoid bony lesion and search the possibility of a concomitant rotator cuff tear.

\section{Surgical technique:}

The patients were placed in the beach chair position, the arm on the side to operate is draped free to allow intraoperative abduction and external rotation and small towel is placed between the scapula and the table in order to stabilize it. All the patients were approached by deltopectoral approach (Figure 1). After having removed the cephalic vein laterally and ligated its medial branches, the coracoacromial ligament (CAL) is exposed (Figure 2), the arm in external rotation and abduction, and incised 1 $\mathrm{cm}$ from its coracoid attachment to discover then the coracohumeral ligament which is released. To improve exposure on the medial side of the coracoid, the arm is placed in adduction and internal rotation before releasing the pectoralis minor directly from the coracoid process. At this stage the knee of the coracoid should be visible and oscillating saw is used at its level to create a medial to lateral perpendicular osteotomy performing typically a graft with 2.5 to $3 \mathrm{~cm}$ of length. The soft tissue is removed from the inferior surface of the coracoid decorticated in preserving the CAL stump (Figure 3). Then, using a 3.2-mm drill bit, 2 drill holes are made 1 $\mathrm{cm}$ apart in the central axis of the coracoid which is pushed beneath the pectoralis major until required later in the procedure.

To expose the anterior aspect of the glenoid, a subscapularis split is generally practiced in line with its fibers the arm externally rotated at the junction of the superior two-thirds and the inferior one-third and should be performed in the middle of the subscapularis in the case of constitutional hyperlaxity to maximize the effect of the conjoint tendon sling. Thereafter the underlying capsule is incised vertically at the level of the joint line to access to the anteroinferior aspect of the glenoid which is completely exposed at this stage (Figure 4). The anteroinferior labrum and periosteum are excised and the anterior surface of the glenoid is decorticated.

The coracoid is positioned parallel to the glenoid. The first hole is drilled in the glenoid with a 3.2 $\mathrm{mm}$ drill using the inferior hole that has already been made in the coracoid. Drilling is directed 
parallel to the glenoid surface and continued through the posterior cortex. After determining the appropriate screw length, a first screw is fully inserted into the inferior hole in the coracoid graft and in the corresponding hole in the glenoid and tightened into position. After a second check of the coracoid graft positioning which should flush with the glenoid margin without overhang, the second hole is drilled using the superior hole that has already been made in the coracoid to insert the second screw. At this stage, both screws are tightened firmly.

Finally, the stump of the CAL is repaired to the capsule the arm positioned in full external rotation with the elbow by the side, using absorbable sutures. The wound is closed, generally without repairing the split in the subscapularis muscle, and a drain is typically not used unless excessive bleeding is noted.

Postoperatively, the patients are immobilized in a simple sling for 15 days with allowed selfmobilization in elevation and external rotation from day 3 to 1 month. The return to athletic conditioning is done progressively depending on satisfactory healing of the coracoid graft which is usually done around the 3rd month.

\section{Results:}

The mean follow-up was 28 months (range 2432 months). The ten patients ( 6 male and 4 female) were enrolled in this study with a mean age of 25 years (range 18-35 years). The dominant arm was affected in 8 patients (80\%). Five patients $(50 \%)$ were involved in leisure sports. Preoperative average of Instability severity index score (ISIS) (Table 1) was 4.4 (range 3-6). The deficit of the glenoid on preoperative CT scans was on average $20 \%$ (range 10-30\%) and 7 patients present a HillSachs lesion (70\%). At the latest follow-up 8 of the 10 subjects reported a stable shoulder without postoperative complaints especially neurological or infectious. the first patient (10\%) had an anterior dislocation after new traumatic injury and the seconde (10\%) complained of subjective instability without apprehension and recurrent anterior dislocation or subluxation. Functional outcome was assessed using Rowe (Table 2) and Walch-Duplay (Table 3) scores which were on average 92 and 90 respectively. Nine of the ten patients were satisfied $(90 \%)$ and $8(80 \%)$ of them came back to sport at the preinjury level.

\section{Discussion:}

Glenoid bone loss is commonly observed in anterior glenohumeral instability. Its presence increases the recurrence rate of the dislocation episode. In fact, Burkhart and De Beer [7] reported in 2000 on this subject a recurrence rate of $67 \%$ and concluded that glenoid bony deficiency was significant when there was greater than $25 \%$ loss of the inferior glenoid diameter. In this context, The Latarjet procedure which consisting on a transfer of the horizontal limb of the coracoid process with its attached conjoined tendon to the anteroinferior margin of the glenoid, is the first-line treatment in the setting of bone loss ${ }^{[8]}$. This technique can be done according to 3 main methods: open surgery via an anterior approach, by arthroscopy and block fixation with screws and by arthroscopy and block fixation with endobuttons [9, 10,11,12].

The stabilizing mechanism of the Latarjet procedure was explained by a triple effect first proposed by Patte [13]: the bony effect of the horizontal limb of the coracoid process that increasing or restoring the glenoid anteroposterior (AP) diameter, the effect of the conjoint tendon kept attached and which acts as a sling on the inferior subscapularis when the arm is in abduction and external rotation and finally the effect of repairing the capsule to the stump of coracoacromial ligament which remains debated in several publications concerning its role in stability ${ }^{[14,15]}$.

From a technical point of view, it is important to distinguish the open Latarjet procedure as discriped initially in $1954{ }^{[4]}$ from the others coracoid transfer procedures which are represented mainly by first the Bristow technique described by Helfet in $1958{ }^{[16]}$ in which Only the 
cancellous end of the coracoid carring the conjoined tendons were removed then sutured to the anteroinferior edge of the glenoid rim through a vertical slit in the middle two-thirds of the musculofibrous junction of the subscapularis muscle, and secondarily the modified Bristow Helfet procedure reported by Mead ${ }^{[17]}$, Sweeney ${ }^{[17]}$ and May ${ }^{[18]}$, during which bone block is fixed to the anterior glenoid rim with a screw.

The modifications were followed to mainly interest the subscapular muscle transecting and closing, positioning of the coracoid process and its fixation method. In this context Latarjet [19] dissected the subscapular muscle completely with a vertical incision and reattached it with sufficient overlap to get the right amount of muscle tension. Helfet [16] approaches the articulation by a $2.5-3 \mathrm{~cm}$ vertical slit in the middle two-thirds of the musculofibrous junction of the muscle and closes the capsule overlapping when it is voluminous. Additional to the vertical slit, May [18] divides the muscle parallel to its fibres to enable placement of the coracoid graft under direct vision. Young [20] splits the subscapularis in line with its fibres between the superior two-thirds and the inferior one-third. On their part, Torg et al ${ }^{[21]}$ prefers to place the coracoid segment and conjoint tendon above and over the superior border of the subscapular muscle rather than through its fibres, to benefit as the authors report from a better glenohumeral joint exposure, an increased strength of musculotendinous sling, and the possibility of salvage surgery in patients who had a redislocation. In our context, we approach the the articulation through the subscapularis in line with its fibres between the superior two-thirds and the inferior one-third. This guarantees us intraoperatively better glenohumeral joint exposure while preserving the continuity of the muscle fibers which allows postoperatively immediate motion exercises in external rotation.

Concerning the placement of the coracoid process, Mackenzie ${ }^{[22]}$ suggested to position it anteroinferiorly with the concave side facing towards the humerus in order to optimize external rotation. In 2009, De Beer [23] Described "the congruent arc" technique which advocates at the opposite of classic Latarjet technique to rotate the coracoid process $90^{\circ}$ in both the coronal and axial planes, such that the inferior surface of the coracoid graft is flush to the glenoid surface. According to its author, the congruent arc procedure improves the correspondence between the radius of curvature of both the inferior coracoid surface and the glenoid rim and promots a better contact pressures distribution on glenoid articular surface. Biomechanically, the classic and congruent-arc coracoid positioning restore shoulder stability and motion without substantially difference ${ }^{[24]}$. In our patients, after preparation, the coracoid process is tightened into position parallel to the articular margin of the glenoid with no overhang with the concave side facing the humeral head.

Arthroscopic Latarjet procedure for anterior glenohumeral instability has been performed with increasingly good results $[25,26,27,28,29,30,31,32]$. In the litterature, systematic review of cohort studies comparing the open Latarjet procedure to the arthroscopic Latarjet procedure showed the non-existence of a statistically significant difference between the procedures with a mean Rowe score of 92.3 in open Latarjet procedure compared to 85.8 in the case of the arthroscopic Latarjet procedure ${ }^{[3]]}$. The same findings were found in terms of operation time, external range of motion (EROM), total recurrence instability, recurrent dislocations, revisions due to recurrent instability and total complication rates ${ }^{[33]}$. The postoperative pain levels were reported in 2 studies, comprising 107 and 135 cases of open Latarjet procedures and arthroscopic Latarjet procedures respectively [33]. In this context, Marion et al ${ }^{[34]}$ found that there was a significantly lower visual analog scale (VAS) score with the arthroscopic approach in the first week. This difference was observed up to 1 month for Nourissat et al ${ }^{[35]}$. 
Table 1: The instability severity index score (ISIS)

\begin{tabular}{|c|c|}
\hline Prognostic factor & Points \\
\hline \multicolumn{2}{|l|}{ Age at surgery (years) } \\
\hline$\leq 20$ ans & 2 \\
\hline$>20$ ans & 0 \\
\hline \multicolumn{2}{|c|}{ Degree of sport participation (pre-operative) } \\
\hline Competitive & 2 \\
\hline Recreational or none & 0 \\
\hline \multicolumn{2}{|l|}{ Type of sport (pre-operative) } \\
\hline Contact of forced overhead & 1 \\
\hline Other & 0 \\
\hline \multicolumn{2}{|l|}{ Shoulder hyperlaxity } \\
\hline Hyperlaxity & 1 \\
\hline Normal laxity & 0 \\
\hline \multicolumn{2}{|c|}{ Hill-Sachs on anteroposterior radiograph } \\
\hline Visible on external rotation & 2 \\
\hline Not visible on external rotation & 0 \\
\hline \multicolumn{2}{|c|}{ Loss of glenoid contour on anteroposterior radiograph } \\
\hline Loss of contour & 2 \\
\hline No lesion & 0 \\
\hline Total & 10 \\
\hline
\end{tabular}

Table 2: The Rowe score

\begin{tabular}{|l|l|l|}
\hline Items & \multicolumn{2}{|l|}{ Score (points) } \\
\hline \multirow{5}{*}{ stability } & No recurrence, subluxation or apprehension & 50 \\
\cline { 2 - 3 } & Apprehension when placing arm in certain positions & 30 \\
\hline \multirow{5}{*}{ Mobility } & Subluxation & 10 \\
\cline { 2 - 3 } & True recurrence & 0 \\
\hline & $\begin{array}{l}100 \% \text { of normal external rotation, internal rotation and } \\
\text { elevation }\end{array}$ & 20 \\
\cline { 2 - 3 } & $\begin{array}{l}75 \% \text { of normal external rotation, internal rotation and } \\
\text { elevation }\end{array}$ & 15 \\
\cline { 2 - 3 } & $\begin{array}{l}50 \% \text { of normal external rotation and 75\% of internal } \\
\text { rotation and elevation }\end{array}$ & 5 \\
\cline { 2 - 3 } & $\begin{array}{l}50 \% \text { of internal rotation and elevation and no external } \\
\text { rotation }\end{array}$ & 0 \\
\hline Function & No limitation in work and sport, little or no pain & 30 \\
\cline { 2 - 3 } & Mild limitation, little pain & 25 \\
\cline { 2 - 3 } & Moderate limitation & 10 \\
\cline { 2 - 3 } & Marked limitation and pain & 0 \\
\hline
\end{tabular}


Table 3 : The Walch-Duplay score

\begin{tabular}{|c|c|c|}
\hline \multicolumn{2}{|l|}{ Items } & \multirow{2}{*}{$\begin{array}{l}\text { Score (points) } \\
25\end{array}$} \\
\hline Sport or daily activity & Return to same sport level & \\
\hline & Or no discomfort & 25 \\
\hline & Back to same sport, but at a decreased level & 15 \\
\hline & Slight discomfort in forceful movements & 15 \\
\hline & Change in sport & 10 \\
\hline & Slight discomfort during simple movements & 10 \\
\hline & Stop sport & 0 \\
\hline & Slight discomfort during simple movements & 0 \\
\hline \multirow[t]{4}{*}{ Stability } & No apprehension & 25 \\
\hline & Persistent apprehension & 15 \\
\hline & Feeling of instability & 0 \\
\hline & True recurrence & -25 \\
\hline \multirow[t]{3}{*}{ Pain } & No pain or pain during certain climatic conditions & 25 \\
\hline & Pain during forceful movements or when tired & 15 \\
\hline & Pain during daily life & 0 \\
\hline \multirow[t]{4}{*}{ Mobility } & $\begin{array}{l}\text { Pure frontal abduction against a wall : symmetrical } \\
\text { Internal rotation }(\mathrm{IR}) \text { : limitation }<3 \text { vertebrae } \\
\text { External rotation in abduction (ER2) : limitation to }<10 \% \\
\text { of the controlateral side }\end{array}$ & 25 \\
\hline & $\begin{array}{l}\text { Pure frontal abduction against a wall }<150^{\circ} \\
\text { IR limitation }<3 \text { vertebrae } \\
\text { ER2 limitation to }<30 \% \text { of the controlateral side }\end{array}$ & 15 \\
\hline & $\begin{array}{l}\text { Pure frontal abduction against a wall }<120^{\circ} \\
\text { IR limitation }<6 \text { vertebrae } \\
\text { ER2 limitation to }<50 \% \text { of the controlateral side }\end{array}$ & 5 \\
\hline & $\begin{array}{l}\text { Pure frontal abduction against a wall }<90^{\circ} \\
\text { IR limitation }>6 \text { vertebrae } \\
\text { ER2 limitation }<50 \% \text { of the controlateral side }\end{array}$ & 0 \\
\hline
\end{tabular}




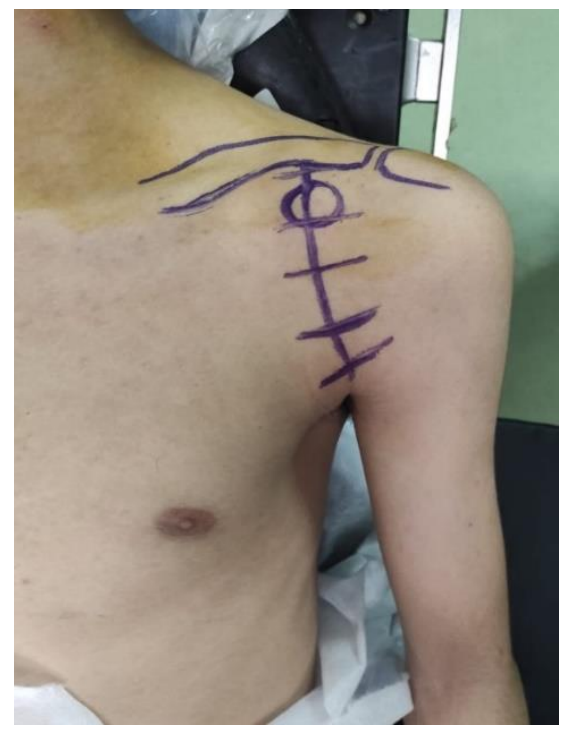

Figure 1 : Marking of the deltopectoral skin incision

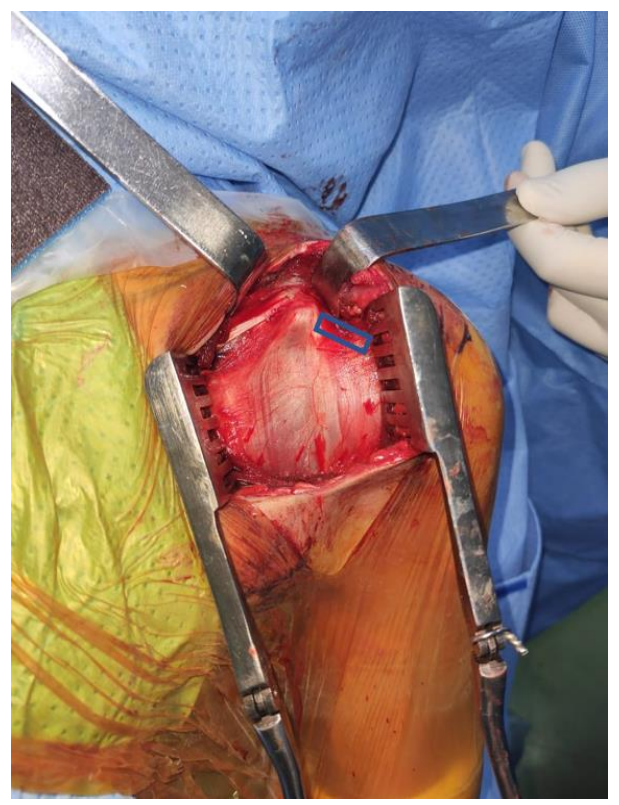

Figure 2 : Exposure of the coracoacromial ligament (CAL), the arm in external rotation and abduction.

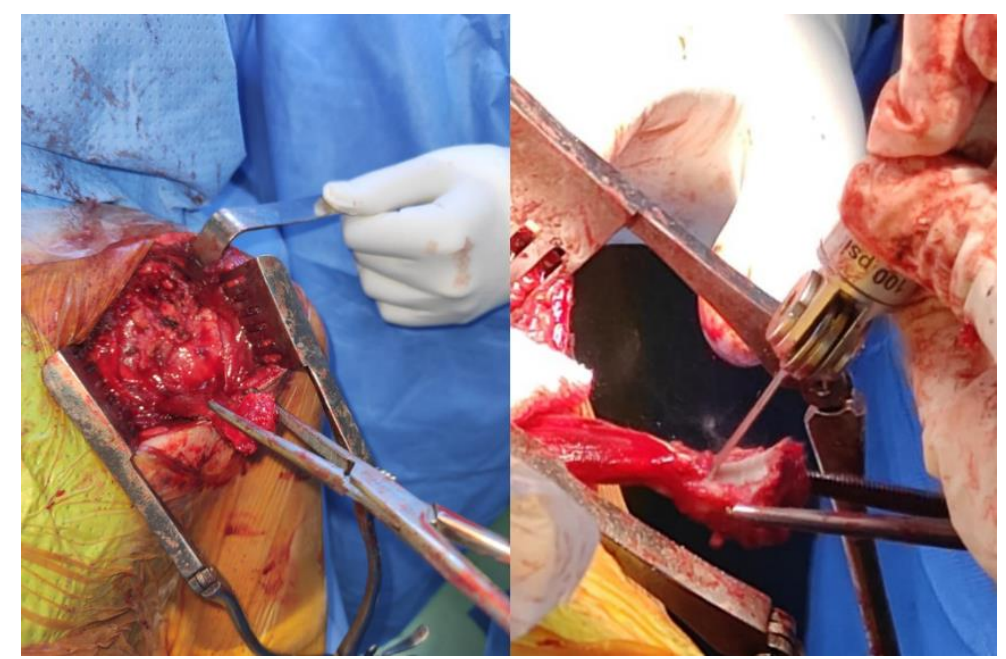

Figure 3 : Preparation of the coracoid graft with a saw 


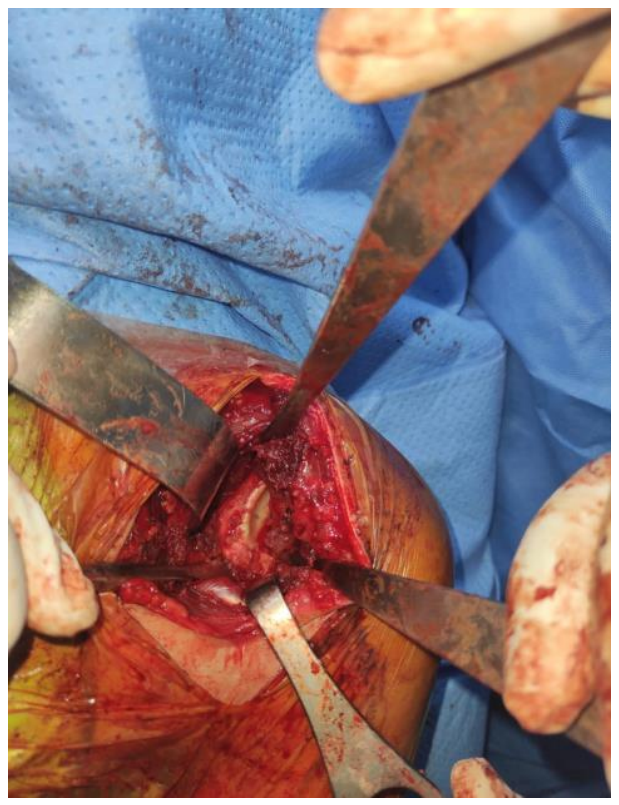

Figure 4 : Exposure of the anterior aspect of the glenoid

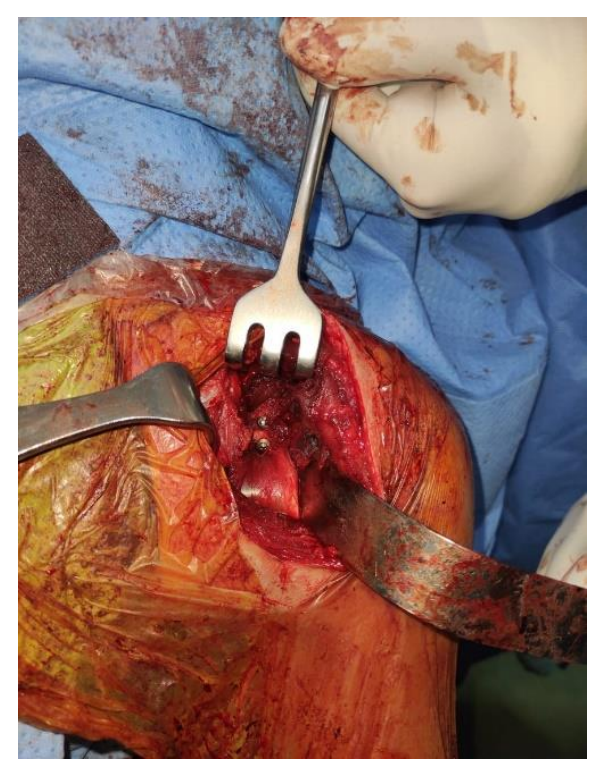

Figure 5 : Double screw fixation of the coracoïde graft

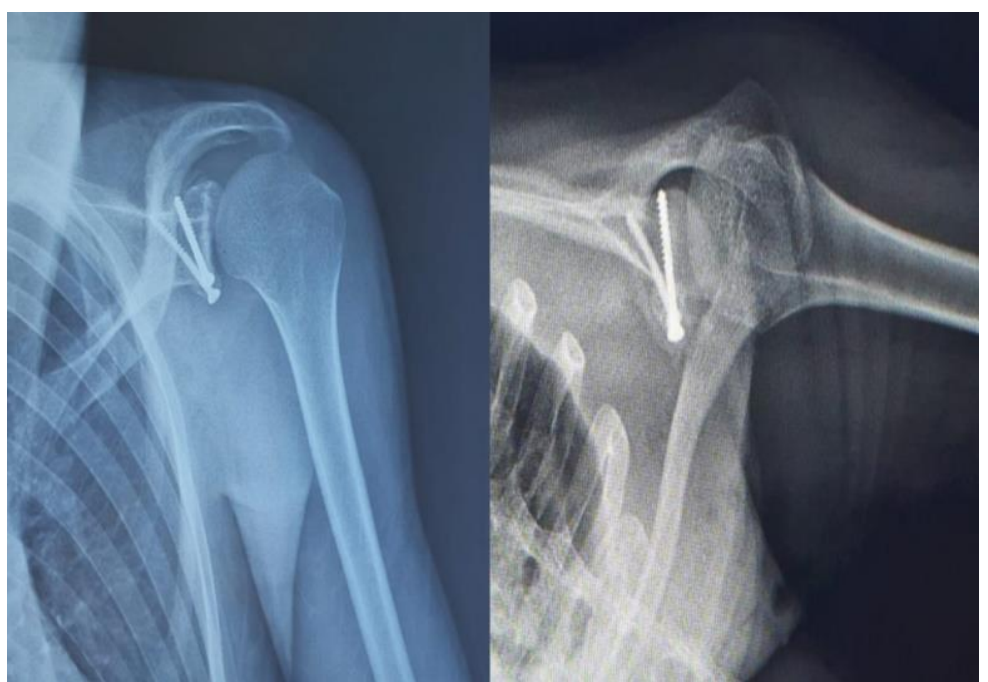

Figure 6 : Postoperative radiographs show the Latarjet procedure 
Boileau et al [12] have identified several drawbacks to arthroscopic Latarjet procedure represented by the technical difficulty of positioning the screws parallel to the articular surface with all the complications that can result from this such as rapid-onset humeral head arthropathy from screw impingement [36,37,38], graft malpositioning ${ }^{[36,37,39]}$, graft migration ${ }^{[40,41]}$, coracoid fracture and screw pullout or loosening $[40,41]$, in addition to a high risk of nerve injury due to the proximity of the drilling lines and screw insertion sites to the brachial plexus ${ }^{[11,42]}$. In our center, the shoulder arthroscopy as a therapeutic tool is not performed routinely, for this reason we practice the Latarjet procedure using an exclusively open approach.

To avoid the complications related to screwing fixation under arthroscopy during Latarjet procedure, the endobutton system has been developped as an alternative ${ }^{[12,43,44]}$. At the base of vitro biomechanical studies which compare the traditional double-screw technique with the endobutton fixation technique of anterior glenoid bone block in terms of graft displacement after the Latarjet procedure, the results indicate that the endobutton system provides comparable fixation stability to double screws ${ }^{[45,46]}$ when conjoint tendon loading is minimized in the early phases of graft healing by conducting an associated labral repair, restricting heavy lifting, or ensuring shoulder immobilization with a sling [45]. In the opposite case, a rotational moment was generated at the inferior tendon insertion site resulting in some graft displacement ${ }^{[45]}$.

Straddling the two aforementioned procedures, namely the arthroscopic technique which allows better positioning of the bony tunnels and the open procedure which provides the advantage of a better preparation of the graft, emerges the arthroscopically assisted Latarjet procedure which can be a real therapeutic option in subjects with anterior glenohumeral instability and glenoid bone defect [47]. This technique combines a mini-open approach useful for preparing the graft safely and therefore avoiding the risk of nerve injuries due to the use of portals medial to the coracoid during the arthroscopic technique, and an arthroscopic approach which improve through an arthroscopic guide the precision of the bony tunnels in the glenoid and coracoid placement in order to decrease the risk of non-union and graft resorption ${ }^{[47]}$.

In terms of complications a recent large systematic review reported an overall complication rate in the open Latarjet procedure of $15 \%$ [49]. Intraoperatively, graft-related complications and vasculo-nerve injuries are the main complications of Latarjet procedure. Too medial graft positioning has a reported incidence of around $5-6 \%{ }^{[40,49]}$ while the rate of too lateral overhang has been reported in the order of 10 to $53 \%{ }^{[40,50]}$ of Latarjet cases. Generally, the graft should be positioned in the case of right shoulder between the 2 o'clock and 5 o'clock position at the level of the glenoid subchondral plate [51]. The reported rate of graft fracture is $1.5 \%$ [52]. For this, Care must be taken during graft preparation avoiding excessive decortication. In addition, a minimum distance between the drill holes must be respected as noted by Walch et al [53] and Lafosse et al [54] who reported respectively the mean distance of $7.8 \pm 1.9 \mathrm{~mm}$ and $9 \mathrm{~mm}$. Regarding neurovascular injury across open and arthroscopic techniques, Griesser et al [52] reported in a systematic review a rate of $1.4 \%$ which predominate in musculocutaneous, axillary and radial nerves as well as at the level of axillary artery. Postoperatively, the literature review highlights the predominance of delayed complications after open or arthroscopic Latarjet procedure especially superficial infection, graft nonunion, graft osteolysis and redislocation reported respectively with rates of $6 \%{ }^{[55],} 9.1 \%{ }^{[52]}$, $59.5 \%{ }^{[56]}$ and $5 \%{ }^{[39]}$. Concerning glenohumeral arthritis, Walch et al reported an incidence of 20 $\%$ at 20 years ${ }^{[36,56]}$. In terms of long-term outcomes of the open Latarjet procedure for anterior shoulder instability, several systematic reviews were conducted for variable duration of follow-up ${ }^{[33,56,59]}$. All conclude to the reliability of the open Latarjet procerdure which provides 
excellent functional outcomes. Rollick et al ${ }^{[58]}$ and Hurley et al ${ }^{[33]}$ reported respectively an average Rowe score of 87.9 and 92.3 with a high overall rate of return to sport of around $88.8 \%$ after 5.8 months on average ${ }^{[59]}$. At the latest follow-up (28 months on average), 8 of the 10 subjects $(80 \%)$ reported a stable shoulder without postoperative complaints, one patient $(10 \%)$ had an anterior dislocation after new traumatic injury and a seconde one (10\%) complained of subjective instability without apprehension and recurrent anterior dislocation or subluxation. In our series, functional Rowe and Walch-Duplay scores were on average 92 and 90 respectively. Nine of the ten patients were satisfied $(90 \%)$ and $8(80 \%)$ of them came back to sport at the preinjury level.

\section{Conclusion:}

The open Latarjet procedure represents a simple, reliable and reproducible surgical technique for the management of anterior instability of the gleno-humeral joint especially in young patients. With great conviction, we practice this procedure with a view to a large series and a possible extension of its indication to an older population.

\section{References:}

[1] Dumont GD, Russell RD, Robertson WJ. Anterior shoulder instability: a review of pathoanatomy, diagnosis and treatment. Curr Rev Musculoskelet Med. 2011;4(4):200-207.

[2] Provencher MT, Bhatia S, Ghodadra NS, et al. Recurrent shoulder instability: current concepts for evaluation and management of glenoid bone loss. J Bone Joint Surg Am. 2010;92(23):133-151.

[3] Sisk TD. Campbell's Operative Orthopaedics. 6th edition. St. Louis, Mo, USA: The C. V. Mosby; 1980. Knee injuries; pp. 486-488.

[4] M. Latarjet, "Traitement de la luxation récidivante de l'épaule. Treatment of recurrent dislocation of the shoulder." Lyon Chirurgical. 1954;(49) :994997.

[5] Gagey OJ, Gagey N. The hyperabduction test. J Bone Joint Surg Br. 2001;831:69-74.

[6] Bernageau J, Patte D, Bebeyre J. Interet du profile glenoidien dans le luxations recidivantes de l'epaule. Rev Chir Orthop. 1976;62:142-7.
[7] Burkhart SS, De Beer JF. Traumatic glenohumeral bone defects and their relationship to failure of arthroscopic Bankart repairs: significance of the inverted-pear glenoid and the humeral engaging Hill-Sachs lesion. Arthroscopy. 2000;16:677-94.

[8] Provencher MT, Bhatia S, Ghodadra NS, et al. Recurrent shoulder instability: current concepts for evaluation and management of glenoid bone loss. J Bone Joint Surg Am. 2010;92(23):133-151.

[9] Lafosse L, Lejeune E, Bouchard A, Kakuda C, Gobezie R, Kochhar T. The arthroscopic Latarjet procedure for the treatment of anterior shoulder instability. Arthroscopy. 2007;23(11):1242 e11242 e5.

[10] Lafosse L, Boyle S. Arthroscopic Latarjet procedure. J Shoulder Elbow Surg. 2010;19(Suppl.):2-12.

[11] Boileau P, Mercier N, Roussanne Y, Thélu CE, Old J. Arthroscopic Bankart-Bristow-Latarjet procedure: the development and early results of a safe and reproducible technique. Arthroscopy. 2010;26(11):1434-50.

[12] Boileau P, Gendre P, Baba M, Thélu CÉ, Baring T, Gonzalez JF, et al. A guided surgical approach and novel fixation method for arthroscopic Latarjet. J Shoulder Elbow Surg. 2016;25(1):7889.

[13] Patte D, Debeyre J. Luxations récidivantes de l'épaule. Encycl Med Chir Paris. Tech Chir Orthop. 1980;44265:4.4-02.

[14] Kleiner M T, Payne W B, Michelle H. McGarry M $\mathrm{H}$, Tibone $\mathrm{J} \mathrm{E}$, Lee $\mathrm{T} \mathrm{Q}$. Biomechanical Comparison of the Latarjet Procedure with and without Capsular Repair. Clin Orthop Surg. 2016;8:84-91.

[15] Yamamoto N, Muraki T, An K N, Sperling J W, Cofield R H, Itoi E, Walch G, Steinmann S P. The stabilizing mechanism of the Latarjet procedure: a cadaveric study. J Bone Joint Surg Am. 2013;95(15):1390-7.

[16] Helfet AJ. Coracoid transplantation for recurring dislocation of the shoulder. J Bone Joint Surg Br. 1958;40:198-202.

[17] Mead N C, Sweeney H J. Bristow procedure. Spectator letter. The Spectator Society, 1964.

[18] May V R. "A modified Bristow operation for anterior recurrent dislocation of the shoulder". J Bone Joint Surg Am. 1970;52:1010-1016.

[19] Latarjet M. Technic of coracoid preglenoid arthroereisis in the treatment of recurrent dislocation of the shoulder. Lyon Chir. 1958;54:604-607. 
[20] Young AA, Maia R, Berhouet J, Walch G. Open Latarjet procedure for management of bone loss in anterior instability of the glenohumeral joint. $\mathrm{J}$ Shoulder Elbow Surg. 2011; 20:61-69.

[21] Torg JS, Balduini FC, Bonci C, Lehman RC, Gregg JR, Esterhai JL, Hensal FJ. A modified Bristow-Helfet-May procedure for recurrent dislocation and subluxation of the shoulder. Report of two hundred and twelve cases. J Bone Joint Surg Am. 1987; 69:904-913.

[22] Mackenzie DB. Treatment of recurrent anterior shoulder dislocation by the modified BristowHelfet procedure. S Afr Med. 1984;66(2):436.

[23] De Beer JMM, Burkhart SSM, Roberts CPMB, van Rooyen K, Cresswell T, du Toit DF. The congruent-arc Latarjet. Tech Shoulder Elb Surg. 2009;10(2):62-67.

[24] Boons H W, Giles J W, Elkinson I, James A. Johnson J A, Athwal G S. Classic Versus Congruent Coracoid Positioning During the Latarjet Procedure: An In Vitro Biomechanical Comparison. Arthroscopy. 2013;29(2):309-316.

[25] Ahmed I, Ashton F, Robinson C M. Arthroscopic Bankart repair and capsular shift for recurrent anterior shoulder instability: functional outcomes and identification of risk factors for recurrence. $J$ Bone Joint Surg Am. 2012;94:1308-15.

[26] Castagna A, Markopoulos N, Conti M, Delle Rose G, Papadakou E, Garofalo R. Arthroscopic Bankart suture-anchor repair: radiological and clinical outcome at minimum 10 years of followup. Am J Sports Med. 2010;38:2012-6.

[27] Kavaja L, Pajarinen J, Sinisaari I, Savolainen V, Bjorkenheim JM, Haapamaki V, et al. Arthrosis of glenohumeral joint after arthroscopic Bankart repair: a long-term follow-up of 13 years. J Shoulder Elbow Surg. 2012;21:350-5.

[28] Kim SH, Ha KI, Cho YB, Ryu BD, Oh I. Arthroscopic anterior stabilization of the shoulder: two to six-year follow-up. J Bone Joint Surg Am. 2003;85:1511-8.

[29] O'Neil DB. Arthroscopic Bankart repair of anterior detachments of the glenoidlabrum: a prospective study. J Bone Joint Surg Am. 1999;81:1357-66.

[30] Porcellini G, Campi F, Pegreffi F, Castagna A, Paladini P. Predisposing factors for recurrent shoulder dislocation after arthroscopic treatment. J Bone Joint Surg Am. 2009;91:2537-42.

[31] Privitera DM, Bisson LJ, Marzo JM. Minimum 10year follow-up of arthroscopic intra-articular Bankart repair using bioabsorbable tacks. Am J Sports Med. 2012;40:100-7.
[32] Voos JE, Livermore RW, Feeley BT, Altchek DW, Williams RJ, Warren RF, et al. Prospective evaluation of arthroscopic Bankart repairs for anterior instability. Am J Sports Med. 2010;38:302-7.

[33] Hurley E T, Fat D L, Farrington S K, Mullett $H$. Open Versus Arthroscopic Latarjet Procedure for Anterior Shoulder Instability A Systematic Review and Meta-analysis. Am. J. Sports Med. 2019;47(5):1248-1253.

[34] Marion B, Klouche S, Deranlot J, Bauer T, Nourissat G, Hardy P. A prospective comparative study of arthroscopic versus mini-open Latarjet procedure with a minimum 2-year follow-up. Arthroscopy.

2016;33(2):269-277.

[35] Nourissat G, Neyton L, Metais P, et al. Functional outcomes after open versus arthroscopic Latarjet procedure: a prospective comparative study. Orthop Traumatol Surg Res. 2016;102(8):277279.

[36] Mizuno N, Denard PJ, Raiss P, Melis B, Walch G. Long-term results of the Latarjet procedure for anterior instability of the shoulder. J Shoulder Elbow Surg. 2014;23:1691e9.

[37] Schmid SL, Farshad M, Catanzaro S, Gerber C. The Latarjet procedure for the treatment of recurrence of anterior instability of the shoulder after operative repair: a retrospective case series of forty-nine consecutive patients. J Bone Joint Surg Am. 2012;94:e75.

[38] Walch G. La luxation recidivante anterieure d'epaule [Recurrent anterior shoulder instability]. Rev Chir Orthop Reparatrice Appar Mot. 1991;77:177e91.

[39] Hovelius L, Sandstrom B, Olofsson A, Svensson $\mathrm{O}$, Rahme $\mathrm{H}$. The effect of capsular repair, bone block healing, and position on the results of the BristowLatarjet procedure (study III): long-term follow-up in 319 shoulders. J Shoulder Elbow Surg. 2012;21:647e60.

[40] Allain J, Goutallier D, Glorion C. Long-term results of the Latarjet procedure for the treatment of anterior instability of the shoulder. J Bone Joint Surg Am. 1998;80(6):841-52.

[41] Athwal GS, Meislin R, Getz C, Weinstein D, Favorito $P$. Short-term complications of the arthroscopic Latarjet procedure: a North American experience. Arthroscopy 2016;32:1965e70.

[42] Boileau P, Mercier N, Old J. Arthroscopic Bankart-Bristow-Latarjet (2B3) procedure: how to do it and tricks to make it easier and safe. Orthop Clin North Am 2010;41:381e92. 
[43] Hardy A, Sabatier V, Schoch B, Vigan M, Werthel JD, Nourissat G, et al. Latarjet with cortical button fixation is associated with an increase of the risk of recurrent dislocation compared to screw fixation. Knee Surg Sports Traumatol Arthrosc. 2020;28:2354e60.

[44] Valenti P, Maroun C, Wagner E, Werthel JD. Arthroscopic Latarjet procedure combined with Bankart repair: a technique using 2 cortical buttons and specific glenoid and coracoid guides. Arthrosc Tech. 2018;7:e313e20.

[45] Reeves J M, Athwal G S, Johnson J A. Doublescrew and quadruple-button fixation for the glenoid: Latarjet versus bone block applications. JSES Int. 2020; 4(4): 780-785.

[46] Provencher MT, Aman ZS, LaPrade CM, Bernhardson AS, Moatshe G, Storaci HW, et al. Biomechanical comparison of screw fixation versus a cortical button and self-tensioning suture for the Latarjet procedure. Orthop J Sports Med. 2018;6(6):2325967118777842.

[47] Taverna E, Longo U G, Guarrella V, Garavaglia G, Perfetti C, Sconfienza L M, Broffoni L, Denaro $V$. A new mini-open technique of arthroscopically assisted Latarjet. BMC Musculoskelet Disord. 2020; 21:285.

[48] Longo UG, Loppini M, Rizzello G, Ciuffreda M, Berton A, Maffulli N, et al. Remplissage, humeral osteochondral grafts, weber osteotomy, and shoulder arthroplasty for the management of humeral bone defects in shoulder instability: systematic review and quantitative synthesis of the literature. Arthroscopy. 2014;30(12):1650-66.

[49] Hovelius L, Korner L, Lundberg B, Akermark C, Herberts $\mathrm{P}$, Wredmark $\mathrm{T}$, et al. The coracoid transfer for recurrent dislocation of the shoulder. Tech Asp Bristow-Latarjet Proced. J Bone Joint Surg Am. 1983;65(7):926-34.

[50] Cassagnaud X, Maynou C, Mestdagh H. Clinical and computed tomography results of 106 LatarjetPatte procedures at mean 7.5 year follow-up. Rev Chir Orthop Reparatrice Appar Mot. 2003;89(8): 683-92.
[51] Gupta A, Delaney R, Petkin K, Lafosse L. Complications of the Latarjet procedure. Curr Rev Musculoskelet Med. 2015; 8:59-66.

[52] Griesser MJ, Harris JD, McCoy BW, Hussain WM, Jones MH, Bishop JY, et al. Complications and re-operations after Bristow-Latarjet shoulder stabilization: a systematic review. J Should Elbow Surg Am. 2013;22(2):286-92.

[53] Young AA, Baba M, Neyton L, Godeneche A, Walch G. Coracoid graft dimensions after harvesting for the open Latarjet procedure. J Should Elbow Surg Am. 2013;22(4):485-8.

[54] Rosso C, Bongiorno V, Samitier G, Dumont GD, Szollosy G, Lafosse L. Technical guide and tips on the all-arthroscopic Latarjet procedure. Knee Surg Sports Traumatol Arthrosc. 2016;24(2):56472.

[55] Shah AA, Butler RB, Romanowski J, Goel D, Karadagli D, Warner JJ. Short-term complications of the Latarjet procedure. J Bone Joint Surg Am. 2012;94(6):495-501.

[56] Di Giacomo G, Costantini A, de Gasperis N, De Vita A, Lin BKH, Francone M, et al. Coracoid graft osteolysis after the Latarjet procedure for anteroinferior shoulder instability: a computed tomography scan study of twenty-six patients. J Should Elbow Surg Am. 2011;20(6):989-95.

[57] Leroux T, Wasserstein D, Veillette $C$, Khoshbin $A$, Henry $P$, Chahal $J$, et al. Epidemiology of primary anterior shoulder dislocation requiring closed reduction in Ontario, Canada. Am J Sports Med. 2014;42(2): 442-50.

[58] Rollick N C, Ono $\mathrm{Y}$, Kurji H M, Nelson A A, Boorman R S, Thornton G M, Lo I K. Long-term outcomes of the Bankart and Latarjet repairs: a systematic review. Open Access J Sports Med. 2017;8:97-105.

[59] Hurley E T, Shimozono Y, Montgomery C, Jamal M S, Ali Z, Pauzenberger L, Mullett $H$. Return to Sport After Surgical Treatment for Anterior Shoulder Instability: A Systematic Review: Letter to the Editor. Am J Sports Med. 2019;47(3):NP23NP24.

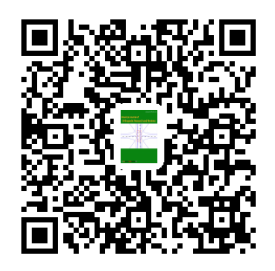

